\title{
Managing for risk on summer dry coastal hill country
}

\section{KINNELL}

Waimimi, R.D. 12, Masterton

\begin{abstract}
The purpose of the paper is to demonstrate that "risk management" on summer dry hill country is achieved through the implementation of very simple policies. The conclusions that I have reached are the result of 20 years of farming on such country, reinforced through careful observation of local farm discussion groups.
\end{abstract}

Keywords: summer dry coastal hill country

My aim is to achieve profitability by:

(a) maximising profits in average years

(b) avoiding disaster in drought years

The correct farming strategy for the average year is more important than for the drought year because there are more average years than drought years.

The correct strategy for the average season is to simply align livestock requirements with average pasture production. The tricky bit is to do this profitably. The stock policy on the farm will have a major effect on this strategy.

Average season pasture production on summer dry hill country $(\mathrm{SDCH})$ is:

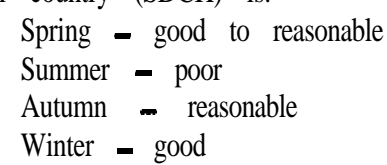

The key to matching livestock requirements to this growth pattern is to reduce to winter carrying capacity by Christmas.

\section{Sheep policy}

The breeding ewe is the animal best suited to SDCH providing that the ewe is in top condition by Christmas. This is easily achieved by:

1. lambing late, weaning and selling lambs early

2. good pasture cover at lambing (not often achieved), resulting in more lambs of better quality and higher ewe live weights at weaning.

The key component in the profitability of this system is a consistently high lambing percentage (see Table 1 which demonstrates profitability of lambing percentage versus lamb price).
Table 1 (Based on 35 ewe lambs retained per 100 ewes)

\begin{tabular}{ccc}
\hline Lambing percent & Average price & Total return \\
\hline $60 \%$ & 72.00 & $1,800.00$ \\
$70 \%$ & 51.43 & $1,800.00$ \\
$60 \%$ & 40.00 & $1,800.00$ \\
$90 \%$ & 32.73 & $1,800.00$ \\
$100 \%$ & 27.69 & $1,800.00$ \\
$110 \%$ & 24.00 & $1,800.00$ \\
$120 \%$ & 21.16 & $1,800.00$ \\
$130 \%$ & 16.95 & $1,800.00$ \\
\hline
\end{tabular}

The hogget does not fit the SDCH at all well. The hogget requires:

(a) quality feed in the summer (often in short supply), and may be prone to grass staggers

(b) high feed levels relative to a ewe in the winter, consequently lowering pasture cover levels at lambing.

The best hogget policy is to run sufficient for replacements for your ewe flock and no more. The economics of farming extra hoggets for sale in the spring looks attractive only when compared with a mediocre flock of ewes.

Surprisingly, the mating of hoggets is well suited to SDCH as the only extra feed requirement occurs in the spring.

\section{Cattle policy}

The breeding cow is an essential tool in the management of SDCH, and can also be profitable. However, the breeding cow does not fit well into the SDCH pasture growth pattern.

The breeding cow has high feed requirements when feeding a calf over the summer. This problem is mitigated to some extent by the ability of the breeding cow to convert low quality dry feed into good growth rates in the calf, providing that the cow is in top condition by Christmas.

The SDCH farmer can to a large extent achieve the aim of winter carrying capacity by Christmas through a cattle policy that entails the sale of fat 18- or 30-month cattle prior to Christmas, the 18-month policy being the better option.

Bull beef has advantages (especially the 1-year policy) and disadvantages over the breeding cow. The advantages of bull beef are: 
(a) the weaner bull has low feed requirements over the summer

(b) the bull does not suffer the metabolic problems of a cow in late winter early spring.

The disadvantages are:

(a) the weaner bull requires high quality feed all year (can be a real problem in the summer)

(b) the bull cannot profitably utilise poor quality feed.

The key to profitably cattle farming whether bulls or cows or both, is good pasture cover in the early spring. This enables:

1. the cow calving on good feed, to be in good condition for mating with the ability to convert dry summer feed into good calf growth

2 . the growing bull a head start in late winter and early spring. SDCH does not have reliable growth in the summer to mask management errors in the early spring.

\section{Summary of strategies for the average year}

The key to safe and profitable farming on SDCH is early sale of surplus stock coupled with good condition capital stock by Christmas to cope with the summer dry.

To achieve this end the essential ingredient is good pasture cover in the early spring (much the same as dairy farming).

Good pasture cover in early spring is achieved by the simple management strategies previously outlined and boosted through the use of nitrogen fertiliser.

\section{The drought year}

No matter what, there is always some cost to a drought.

Farmers who follows the conventional summer dry hill management strategies, as already outlined, will be in a better position at the start of a drought than those who do not because they will have:

(a) reduced to winter stock numbers at the onset of a drought

(b) through good spring feeding, ensured that the stock remaining are in better condition to withstand the drought conditions.

Supplementary feed will inevitably be required until the drought breaks. The best form of supplementary feed is silage (it is also the cheapest)

Most, but not all, SDCH farms have an area of flat land. Those farms that cannot make or buy silage have two alternatives:

(i) sell stock

(ii) send stock off for grazing.

Whatever the choice, the early decision is always the best. The person who quits stock early in a drought gets the best price (prices get lower as the drought continues and seldom recover before the following spring), and likewise, the person who seeks grazing early invariably gets the cheapest and best grazing.

A farmer with even a small area of flat should withstand the average drought without much pain (the only cost being the cost of the silage).

The post-drought winter management is probably more important than the drought management itself. Again the early decision is the profitable decision. The problem is two-fold:

1. Stock are in poor condition and are in need of quality feed

2. The grass is short.

The simple answer is to apply nitrogen fertiliser (what rate do you use? do you apply to whole farm?). This should be applied as soon as moisture levels are sufficient to get a response. Delay merely reduces the available time before ground temperatures restrict the effect of the nitrogen.

Sufficient nitrogen should be applied to ensure that the stock that have survived the drought and or grazing, will survive the winter. It is not good business to feed silage, or pay for grazing and then sell those stock in the middle of winter when prices will be very low.

If you have been forced to destock then the time to replace is before everyone else does. Stock prices generally remain depressed through the winter, and it may well be good practice to boost your pasture with nitrogen, and replace your stock in the depths of the winter. If you wait until everyone has grass you will be purchasing on a grass market.

\section{Summary of drought management}

1. Have a stockpile of silage (a small area of flat is all you need)

2. Sell surplus stock before the drought

3. Act quickly with selling and grazing decisions

4. Ensure that the silage or grazing does not finish before the drought

5. To ensure adequate quality pasture for post-drought recovery, apply nitrogen fertiliser as soon as a response is likely

6. Replace stock early before stock prices rise. 